\title{
Negação da política e politização da educação: a prática discursiva do Movimento Escola sem Partido
}

Celso do Prado Ferraz de Carvalho

Universidade Nove de Julho

\section{Resumo}

Neste texto nossa intenção é situar o discurso elaborado pelo Movimento Escola Sem Partido (ESP), que objetiva construir determinada narrativa acerca de temas importantes na educação, especificamente no campo do currículo. Em sua ação ideológica, o ESP defende a despolitização da escola, a separação entre formação e ensino e o discurso sobre o controle da corporeidade, enfatizando as questões de identidade e gênero. Ao tratarmos do movimento em perspectiva histórica, o faremos a partir de dois momentos cruciais para a construção da hegemonia da direita. Inicialmente, recuperamos aspectos importantes do processo de construção do discurso, fundado na racionalidade técnica, elaborado pelo Instituto de Organização Racional do Trabalho (IDORT) na década de 1930. Na sequência, analisamos aspectos que marcaram a construção da ação política do Instituto de Pesquisa e Estudos Sociais (IPES) na década de 1960, sua ação ideológica e as teses que defendeu. Por fim, retomamos ao ESP, e procedemos à análise de algumas das teses que defendem e os limites que elas expressam.

Palavras-chave: Escola sem partido. Disciplinarização. Currículo. Corporeidade.

\section{Denial of politics and politicization of education: the discursive prac- tice of the School without Party Movement}

\begin{abstract}
In this text, our intention is to situate the discourse elaborated by The School Without Party Movement (Movimento Escola Sem Partido - ESP), which aims to construct a certain narrative about important themes in education, specifically in the curriculum field. In its ideological action, the ESP defends the depoliticization of the school, the separation between the formation and the teaching and the discourse about the control of the corporeity, emphasizing the questions of identity and gender. When we deal with the movement in a historical perspective, we will do it from two crucial moments for the construction of the right-wing politics hegemony. Initially, we recovered important aspects of the process of construction of the discourse, based on technical rationality, elaborated by the Rational Organization of Labor Institute (Instituto de Organização Racional do Trabalho-IDORT) in the 1930's. After that, we analyzed aspects that marked the political action construction of the Research and Social Studies Institute (Instituto de Pesquisa e Estudos Sociais IPES) in the 1960's, its ideological action and the theses it defended. Finally, we return to the ESP, and proceed to the analysis of some of the theses that they defend and the limits that they express. Keywords: School Without Party. Disciplinarization. Curriculum. Corporeity.
\end{abstract}


Negação da política e politização da educação: a prática discursiva do Movimento Escola sem Partido

\section{Negación de la política y politización de la educación: la práctica discursiva del Movimiento Escuela Sin Partido}

\section{Resumen}

En este texto, nuestra intención es situar el discurso elaborado por el Movimiento Escuela Sin Partido (Movimento Escola Sem Partido - ESP), que objetiva construir determinada narrativa acerca de temas importantes en la educación, específicamente en el campo del currículo. En su acción ideológica, el ESP defiende la despolitización de la escuela, la separación entre formación y la enseñanza y el discurso sobre el control de la corporeidad, enfatizando las cuestiones de identidad y género. Al tratar del movimiento en perspectiva histórica, lo haremos a partir de dos momentos cruciales para la construcción de la hegemonía de la derecha. En primer lugar, recuperamos aspectos importantes del proceso de construcción del discurso fundado en la racionalidad técnica, elaborado por el Instituto de Organización Racional del Trabajo (Instituto de Organização Racional do Trabalho - IDORT) en la década de 1930. En la secuencia, analizamos aspectos que marcaron la construcción de la acción política del Instituto de Investigación y Estudios Sociales (Instituto de Pesquisa e Estudos Sociais - IPES) en la década de 1960, su acción ideológica y las tesis que defendió. Por último, retomamos al ESP, procedimos al análisis de algunas de las tesis que defienden y los límites que ellas expresan.

Palabras clave: Escuela Sin Partido. Disciplinamento. Plan de estudios. Corporeidad.

\section{Introdução}

Em tempo marcado pelo avanço do pensamento conservador, olhar para a história pode nos ajudar a compreender como os discursos produzidos visam legitimar esse pensamento. Entendemos esse avanço não como mera expressão datada, mas como expressão da atualização histórica de práticas exercidas por diferentes instituições, em outros tempos, com outros objetivos e outros personagens. As expressões do pensamento conservador e sua enorme visibilidade são partes desse processo de atualização histórica. $\bigcirc$ processo golpista, acelerado pela direita a partir de sua derrota nas eleições presidenciais de 2014, foi alimentado por diversos meios e interesses, mobilizou quantidade significativa de ações e recursos, e deu visibilidade e legitimidade a grupos e siglas, até então, pouco conhecidos. $\bigcirc$ Movimento Brasil Livre (MBL), o Vem Pra Rua, o Revoltados on-line e outros de menor expressão ocuparam e utilizaram as denominadas mídias sociais e espaço significativo nos meios de comunicação da denominada grande imprensa.

Esses movimentos contribuíram para a construção de uma narrativa, cujo objetivo inicial foi desconstruir e minar o apoio social que ostentava o 
chamado lulismo, especificamente entre as camadas mais pobres da população. Incorporamos, aqui, a compreensão do lulismo, feita por André Singer que o define como a expressão ampla e complexa de um projeto político, cuja base social mais ampla situa-se nos trabalhadores mais empobrecidos, e que objetivou combater e superar a miséria, sem, contudo, modificar a distribuição da propriedade. Dessa forma, segundo o autor, o projeto reformista, ao propor políticas que não tencionam os interesses estabelecidos, enfraqueceu qualquer possibilidade de confronto com a burguesia, assumindo as feições de um reformismo ativo no combate à miséria e na defesa da ordem (SINGER, 2012). Definido o lulismo como inimigo, iniciou-se o processo de desconstrução, que enfatizava, inicialmente, o caráter corrupto dos governos petistas. $\mathrm{Na}$ sequência, o discurso procurou disseminar a tese de que o lulismo produziu a divisão do país entre ricos e pobres, culminando na narrativa de que o lulismo, ao apoiar políticas de gênero e identidade, especificamente na educação, disseminou valores que contrariavam os princípios da família brasileira.

No contexto de acirramento da luta política, que levou ao golpe de abril de 2016 e à derrota do lulismo, outros grupos e ideias que estavam adormecidas, foram revigoradas, passando a contar com espaços mais amplos de divulgação. Entendemos que esse contexto pode ajudar na compreensão das razões pelas quais o movimento Escola Sem Partido (ESP) assumiu relevância no debate político, especificamente no que concerne às questões educacionais. Até então pouco mencionado, o movimento, por meio de ações de propaganda nas mídias sociais, pela incorporação de suas teses por representantes da direita no Congresso Nacional, nas Assembleias legislativas e diversas Câmaras de Vereadores, passou a ter uma presença mais efetiva, disputando o controle de narrativas em aspectos importantes da organização social, como a educação.

Surgido de forma soturna, em 2003, pela ação do advogado Miguel Francisco Urbano Nagib, o ESP recebeu, inicialmente, pouca atenção. Passou grande parte dos anos de hegemonia do lulismo agindo nas trevas da luta política, até encontrar maior ressonância de suas ideias, para que a luta pela desestabilização política avançasse no governo Dilma Roussef. Definido o caminho para o golpe, as ações e ideias do ESP ganharam notoriedade e se constituíram em uma das faces do discurso da direita.

Nesse contexto recente, a preocupação em entender, criticamente, contribuiu para o movimento se ampliar, ensejando diferentes leituras e 
Negação da política e politização da educação: a prática discursiva do Movimento Escola sem Partido

publicações. Assim, aspectos os mais diversos foram abordados, como, por exemplo, o fato de ser o ESP a expressão autoritária de uma parcela da direita brasileira, interessada em levar a luta política a espaços escolares por ela não controlados. Nesse sentido, seu objetivo é controlar o trabalho dos professores, na expectativa de fragilizar sua ação política, visando, também, interferir no debate acerca da necessidade de se controlar os espaços públicos e, assim, defender a pseudossuperioridade presente nas formas privadas de organização social. Outro aspecto vital que já discutimos é a defesa que o movimento faz da necessidade de separar formação e conteúdo. Formação seria responsabilidade da família, e conteúdo responsabilidade da escola. Nesse processo, a análise feita mostra como o discurso do ESP tem estruturado sua crítica ao anunciado predomínio ideológico da esquerda no debate curricular e sua pretensa hegemonia nos espaços de formação. Por fim, outros textos exploram como a crítica à diversidade cultural e à denominada ideologia de gênero tornaram-se a base de sua ação política nas disputas pela definição da Base Nacional Curricular Comum. São vários e importantes textos que, na contramão do que prega o ESP, partidarizam o debate, visando tomar partido e posição. Como textos relevantes para esse debate, mencionamos, entre outros,

68 os livros organizados pela Ação educativa (2016) e por Frigotto (2017).

Em tempos de produção discursiva ampliada, o controle sobre os discursos é fundamental na política da direita. Definir o que se pode falar e quem pode falar é meio para legitimar o discurso que predomina. Não é um fato novo, pois, em diferentes momentos da história, esse controle foi crucial para a manutenção do poder político pela direita. $\bigcirc$ que é novo é a forma como o controle é produzido, bem como os sujeitos que atuam na linha de frente dos processos de controle. $O$ ESP, pelas devidas proporções, pode ser uma das formas de expressão atualizadas desse movimento da direita, que busca controlar o discurso e, ao mesmo tempo, impor seu discurso político.

Neste texto, nossa intenção é situar o discurso elaborado pelo ESP em perspectiva histórica, como parte dos processos de controle sobre os discursos elaborados pela direita. Na impossibilidade de abranger o processo, em sua totalidade, o faremos a partir de dois momentos essenciais para a construção da hegemonia da direita. Inicialmente, recuperamos aspectos vitais do processo de construção do discurso, elaborado pelo Instituto de Organização Racional do Trabalho (IDORT) na década de 1930, fundado na racionalidade técnica, como meio de organização da vida social. Na sequência, mostramos 
aspectos que marcaram a construção da ação política do Instituto de Pesquisa e Estudos Sociais (IPES) na década de 1960, sua ação ideológica e as teses defendidas na busca pela hegemonia da direita. Por fim, retomamos ao ESP, analisamos sua proximidade e distanciamento com a ação do IDORT e do IPES, algumas das teses que defende, bem como os limites presentes nas ideias que expressa

\section{O discurso técnico e o controle das ideias na década de 1930}

Diferentemente do que defende o ESP, entendemos que a historicização dos processos sociais é fundamental, pois viabiliza a compreensão da constituição dos mecanismos de produção e reprodução da vida em todo o seu dinamismo. Dessa forma, as relações sociais não podem ser apreendidas tão somente como engrenagem de um processo que apresenta sua origem, constituição e maturação tampouco como um dado preestabelecido, descolado dos interesses dos atores individuais e coletivos que constituem a razão de ser do ser social.

Definir o contexto e sujeitos sociais que participam do processo de constituição da contemporaneidade capitalista não constitui uma ação desinteressada como afirma o ESP; pelo contrário, é uma escolha datada e que responde a inquietações postas pelo atual estágio de desenvolvimento das relações sociais capitalistas. Portanto, discutir a ação da direita e os discursos que constrói ajuda a entender o processo de constituição da modernidade e de qual modernidade ela almeja.

Mas esse não é um processo simples, visto que permeia interesses, classes sociais e condições contraditórias. Ao longo do processo de constituição do capitalismo, a burguesia não foi uma classe social homogênea. Sendo articuladora e, ao mesmo tempo, resultante de um processo social que é historicamente desigual e combinado, carrega consigo as marcas herdadas desse processo. Portanto, ao tratarmos das expressões institucionais e políticas que a formação assume, situamos esse processo no campo da constituição das classes sociais como uma relação histórica. Isso nos leva a analisar o papel que essas instituições orgânicas assumem na constituição do cotidiano e na construção de relações históricas de longa duração. 
Negação da política e politização da educação: a prática discursiva do Movimento Escola sem Partido

A história é exemplar ao mostrar que, se as experiências dos indivíduos estão associadas às relações de produção, e são por estas determinadas, a constituição da consciência que possuem desse processo não segue a mesma razão.

Se os interesses econômicos imediatos das forças políticas da direita possuem certo sentimento de identidade e de proximidade, a partir dos quais articulam seus interesses e suas ações políticas, tal sentimento, por si só, não materializa ações políticas, sendo insuficiente, a partir das experiências singulares, produzir consciência de classe, capaz de estabelecer uma relação de complementaridade entre os interesses singulares e coletivos.

caráter complexo e contraditório dos processos de produção e reprodução da vida social está presente com toda a sua intensidade, na constituição da burguesia como classe social e na disseminação de seus interesses. Por essa razão, eles constituem um obstáculo à formação de uma consciência de classe que extrapole seus interesses imediatos. Essa é uma das razões que ajudam a explicar a emergência de instituições as mais diversas que visam disseminar o pensamento liberal por meio de ações, de intervenção social, ideológica e política. Ao realizarem a defesa dos interesses mais imediatos da 70 direita, essas instituições, também, estão desenvolvendo ações com objetivos de natureza orgânica, construindo a consciência de classe burguesa.

Os interesses e objetivos da burguesia com a educação são muito amplos, podendo ser compreendidos por meio do movimento e das ações que realizam ou mediante as falas/discursos de seus representantes. Para tanto, e a título de exemplificação, utilizaremos, como fundamento, estudos que buscaram compreender os interesses e os movimentos postos em ação pelas elites em sua permanente necessidade de manter e consolidar seu poder, agindo direta, ou indiretamente, por meio da construção de consensos.

Em certo momento da história, a defesa da educação universal, da busca pela igualdade e cidade constituíram-se nas diretrizes fundamentais do liberalismo. Dessa forma, a constituição do sistema escolar e da escola pública estatal assumiu, para, o pensamento liberal, o importante papel de construção do novo homem. Essa forma de compreensão do homem, abstrato e sem história, foi presente em toda a fase inicial de constituição do pensamento liberal em educação. No Brasil, recém-convertido à República, a educação foi alçada pelo imaginário republicano "[...] à condição de agente capaz de 
transformar o indivíduo em cidadão produtivo e consciente de seus direitos e deveres cívicos, capaz, portanto, de exercer a liberdade propiciada pela cidadania" (MORAES, 1981, p. 133). Em um país marcado pelos traços sociais do trabalho escravo e sem um sistema público de ensino, a promessa republicano-liberal era uma das mais ousadas.

O processo de formação do homem republicano, fortemente presente nos discursos e nas reformas educacionais dos anos iniciais da República, articulado por meio de diferentes intelectuais e instituições, que não possuíam idênticos objetivos tampouco empregavam os mesmos meios de ação, faz parte de um momento importante de nossa história. Esse amplo movimento teve os mais diferentes desdobramentos, e seus personagens seguiram caminhos distintos.

Um desses caminhos levou à fundação do IDORT. Estudo efetivado por Antonacci (1993) permite identificar como o IDORT se constituiv em um dos espaços privilegiados de construção do pensamento da direita do período pós1930. O momento de seu surgimento, ou seja, a passagem dos anos 1920 para os anos 1930, é caracterizada pela tentativa de disseminação das ideias de Taylor e de seus seguidores. No Brasil, desde a década 1920, Roberto Simonsen, um dos mais influentes industriais do período, converteu-se em um dos maiores divulgadores dos princípios tayloristas. Na condição de um dos fundadores do Centro das Indústrias do Estado de São Paulo, em 1928, tornou-se seu vice-presidente, e, nos anos seguintes, um dos mais ativos articuladores dos interesses, não só da burguesia industrial, mas, principalmente, do conjunto das classes dominantes.

Concebendo as relações sociais como relações orgânicas e funcionais, a linguagem, construída e disseminada pelo IDORT, incorporou expressões como corpo social, máquina administrativa, órgãos ou membros. Sua ação foi direcionada no sentido de que, por meio da ação de técnicos, não somente o trabalho, como toda a sociedade, deveria ser organizado com base em princípios racionais. As tentativas de disseminar as ideias da racionalização do trabalho começaram pelas empresas privadas, passando pelos serviços públicos e Estado.

Os resultados, alcançados pelas ações do IDORT junto ao Estado, não foram pequenos. Mesmo tendo que enfrentar as enormes resistências surgidas em resposta às suas ações, o instituto reorganizou os serviços públicos em 
Negação da política e politização da educação: a prática discursiva do Movimento Escola sem Partido

São Paulo, ao mesmo tempo que defendia e expandia a aceitação social de seus princípios. Dessa forma, não somente teve acesso à estrutura do Estado, ganhando legitimidade com isso, como também transformou esse espaço em um instrumento para a difusão de suas ideias. Semelhante ao discurso do ESP, hoje, o IDORT se define como despolitizado e desideologizado. Agindo por meio do Estado, reafirmou o discurso do Estado como gestor do bem comum, transformando políticas públicas emanadas e a serviço das classes dominantes em projetos de toda a sociedade. Fez de seu discurso político um discurso técnico. Fez do discurso técnico um instrumento para a racionalização do espaço político. A busca da Vitória da Razão, presente na proposta original do IDORT, ganhava terreno

\section{Produção de discursos e narrativas na década de 1960}

Uma vasta literatura produzida, nas últimas décadas, ensejou uma série de análises e interpretações acerca do golpe de Estado de abril de 1964 e seus desdobramentos, inclusive produção recente, cuja preocupação foi fazer a crítica a leituras e ao revisionismo crescente no debate sobre o golpe 72 de 1964 (MELO, 2014). De modo amplo, há consensos acerca de aspectos que caracterizaram o período e se expressaram, na prática política, por meio da restrição às liberdades de organização e manifestação; por intervenção na composição do poder judiciário e parlamentar; pelo cerceamento da liberdade nas universidades, por meio de ações que truncaram a carreira de diversos professores e alunos. Ademais, faz parte dessas análises a tese de que o movimento estudantil, e suas expressões políticas mais radicais, irromperam a luta armada como meio de responder às ações autoritárias do regime, que sistematizou a prática da tortura como meio de enfrentamento às organizações da esquerda política. No campo da economia política, há certo consenso, também, sobre as ações realizadas pela ditadura no sentido de ampliar o processo de industrialização da economia brasileira via ampliação da presença do capital multinacional, protecionismo da indústria nacional de bens intermediários e regulação estatal. Tudo isso foi realizado em contexto de repressão aos trabalhadores e em suas formas de organização política.

A ação política ideológica do Instituto de Pesquisas e Estudos Sociais (IPES) merece nossa atenção devido à sua participação tanto no processo de desestabilização do governo de João Goulart, como no período pós-golpe, 
especificamente pela ação no campo educacional. A análise feita por Dreifuss (1981), situando e analisando as ações realizadas pelo IPES, as inserem em um contexto mais amplo, cujo impacto, no cenário econômico- político-social de início da década de 1960, constitui um dos estudos mais amplos e significativos do processo que resultou no golpe de Estado de 1964, narrando, com detalhes, como as forças políticas da direita, nacional e estrangeira deflagraram o golpe. Ao situar o contexto político estudado, o autor revela a ação do IPES e sua ação ideológica, fincada em uma narrativa e em um discurso que orientou muitas das práticas da direita golpista, no intuito de desestabilizar o governo de Jango e abrir caminho político para sua derrubada e legitimação do período pós-golpe.

O IPES, foi oficialmente, fundado em 29 de novembro de 1961, como expressão de setores da burguesia, principalmente de São Paulo e Rio de Janeiro. Em sua pauta e discurso, estavam presentes elementos muito comuns aos que, hoje, balizam a ação do ESP: a ênfase na defesa da sociedade cristã, liberal e capitalista e o ataque agressivo às forças políticas da esquerda. No caso do IPES, as forças políticas combatidas foram os comunistas; no caso do ESP, as forças a serem combatidas se articulam em torno do petismo. Em síntese, objetivam a deslegitimarão discursiva das formas de organização dos trabalhadores, especificamente seus sindicatos e os movimentos sociais que lutam para assegurar direitos como a terra, moradia, educação, saúde e trabalho.

apoio que recebeu e legitimou seu discurso foi bem mais amplo que dos grupos que o fundaram. Vários jornais e revistas disseminavam suas ideias e disponibilizavam espaço para seus membros. Além disso, se valeu do amplo alcance das emissoras de rádio, do cinema, de parcela importante de intelectuais de centro e direita, e, também, contou com a simpatia de setores da lgreja católica, que faziam da luta política contra o governo Goulart, um meio de combater, igualmente, também as forças internas da lgreja que nutriam simpatia pelos setores progressistas. $\bigcirc$ objetivo maior de conquista do Estado passava pelo controle do movimento trabalhista. Na linha de argumentação de Dreifuss, José Paulo Netto, em texto publicado, em 2014, situa o IPES em um contexto cuja ação não pode ser vista como episódica e somente voltada à desestabilização do governo de Goulart, mas também como agente decisivo no processo que definiu a estratégia da burguesia e formulou sua ação. 
Negação da política e politização da educação: a prática discursiva do Movimento Escola sem Partido

Fundadas no discurso agressivo ao governo, as ações do IPES disseminaram seu pensamento e se caracterizou pela radicalização do debate, pela elaboração de documentos temáticos e pela elaboração de análises do contexto sócio-econômico-político. Observando as estratégias de ação do ESP, que dispõem de mecanismos de comunicação muito mais rápidos e de expressiva abrangência, verificamos que há muita similaridade nas estratégias de ação.

A presença pública do IPEs, no debate ideológico, era uma de suas faces, mas não a única. Assim como muitos movimentos da direita, nos dias de hoje, suas ações, também, se desenvolveram nos espaços privados de conspiração e de ações de desestabilização. Mais do que defender ideias, o IPES acionou mecanismos de provocação e de controle, visando interferir no processo social por meio do incentivo à denúncia, à vigilância e à desestabilização das ações dos setores, identificados com o governo.

No contexto político de início da década de 1960, o pensamento que orientou as forças de direita, tal como ocorre hoje, se caracterizou pela ação orgânica, pautada em um discurso comum e orientado para a construção de uma narrativa, que legitimasse suas ações, atribuindo-thes caráter de legitimi-

74 dade, embora não de legalidade. O processo de desestabilização política e do golpe foi construído pela face pública do IPES, que, perante a sociedade, se apresentava como instituição formada por empresários, intelectuais, especialistas em políticas públicas e gestão do Estado, cujo discurso público defendia as instituições e o devido processo político. A face oculta do IPES, que agia de forma clandestina, nas sombras, articulava ações com outros grupos, que defendiam a desestabilização do governo e o rompimento com a ordem constitucional.

A face pública do IPES foi apresentada por meio de documento denominado A responsabilidade democrática do empresário, cujo objetivo era construir o discurso de que se tratava de uma instituição apartidária, sem inserção no processo político, preocupada com a defesa de valores educacionais, pautados no civismo, defendidos por empresários patriotas, que não falavam como representantes de classe. Sua missão - a de contribuir com a análise e as propostas para a resolução de problemas sociais, de forma populista e demagógica - foi disseminada pela esquerda como produtos de uma sociedade de classes. Conforme o ESP faz em nosso contexto, o discurso do IPES atacava a esquerda, atribuindo-lhe a divisão do país, a desvalorização da família e 
da moral e a necessária intervenção e controle dos espaços educacionais, da formação e do currículo. Nesse intento, participavam da direção do IPES profissionais vinculados à universidade, além de especialistas em educação, interessados em contribuir com o instituto visando encontrar soluções e colaborar com a solução dos problemas educacionais do país.

Apresentavam o IPES como organização cujo interesse era melhorar a educação, especificamente a educação dos mais pobres, por meio de campanhas e doações e esclarecer os pais acerca dos problemas do país e dos perigos que a educação politizada pela esquerda produzia.

No processo de organização do governo golpista, diversos cargos foram ocupados por representantes do IPES, especificamente na educação. No contexto do pós-golpe, nos anos finais da década de 1960, as ações do instituto, de intervenção na luta ideológica, foram direcionadas para o enfrentamento do contexto de acirramento da luta social, expressa no movimento estudantil e na tentativa de legitimação do processo de repressão ao movimento. Visando construir uma narrativa acerca do caráter subversivo do movimento estudantil e da necessidade da repressão, em 1968, o IPES organiza, na Pontifícia Universidade Católica do Rio de Janeiro, o Simpósio denominado A educação que nos convém. Organizado, com base em várias mesas temáticas, com a presença de militares de alta patente, professores universitários, representantes das organizações empresariais e do governo, o vínculo que identificava o grupo era o fato de eles manifestarem interesse ou serem vinculados à educação. Os dez eixos temáticos trataram de temas diversos afetos à educação, expressando, por meio das falas dos conferencistas, os anseios, desejos e preocupações políticas da direita. A expressão dessas preocupações foi a forma como o movimento estudantil monopolizou as falas, especificamente a dimensão que assumiu na luta política e a constatação de que os jovens estavam sendo atraídos pelo discurso da esquerda.

Chama-nos a atenção, também, as diferentes maneiras apresentadas como forma de contenção do movimento estudantil. Falas que oscilavam entre a repressão pura e simples, como aquela proferida pelo ministro da justiça Luís Antônio da Gama e Silva, e a defesa de uma ação político-ideológica, orientada para esvaziar o movimento, manifestada na fala do representante da PUC. Em ambos os casos, defendiam que a melhor forma de esvaziar o movimento, era atendendo à pauta inicial de reivindicação, centrada em melhorar as condições dos estudantes e ampliar o acesso à universidade. 
Negação da política e politização da educação: a prática discursiva do Movimento Escola sem Partido

A história nos mostra que venceu a tese do enfrentamento e da repressão ao movimento estudantil, expressa entre outras ações, na edição do Ato Institucional n 5, de 13 de dezembro de 1968, e do Decreto-Lei n 477, de 20 de fevereiro de 1969. O primeiro apontava para a legitimação do terror de Estado, enquanto o segundo para a perseguição pura e simples do movimento estudantil dentro das universidades. Na expressão truculenta do ministro da justiça da ditadura, ao afirmar que aos estudantes cabe estudar e não fazer baderna, sintetizava a narrativa que o instituto procurava construir, ou seja, que o movimento estudantil expressava um problema disciplinar e não a crise política da educação.

Nas falas e debates, que mais especificamente trataram da estrutura educacional do país, da organização do sistema de ensino, dos objetivos da educação e de seu financiamento, a narrativa feita situou o debate educacional em contexto amplo, além do imediato enfrentamento do movimento estudantil. Partindo da crítica à forma como a educação universitária estava organizada, construía-se o discurso em defesa de uma universidade, capaz de formar dirigentes, homens de negócios, na versão atualizada do debate, formar empreendedores. Enfatizando o aspecto normativo e prescritivo do 76 discurso em construção, a moral defendida centrava-se na crítica à pretensa expropriação pela esquerda da disciplina e do respeito dos estudantes para com seus professores e pais.

A expressão do discurso do IPES, na construção de uma narrativa de crítica à universidade, a conferência do economista e quadro do governo golpista Roberto Campos, defendeu a tese de que o sistema de ensino deve estar a serviço do desenvolvimento econômico e da formação de capital humano, e não focado na formação geral humanística e de transmissão de uma cultura desinteressada.

Theophilo de Azeredo Santos, membro ativo do IPES, ampliou as críticas à forma de organização da universidade brasileira. Para ele, era necessário reformar a universidade e modificar os processos metodológicos e de aprendizagem, passando pelos currículos, pela organização da carreira docente e pelo monopólio do professor na definição do ensino praticado. No modelo de educação que considerava mais bem adequado ao país, tal como o ESP alardeia hoje, era preciso interferir e controlar o que era ensinado, bem como a relação dos professores com os alunos. 
Fazer a crítica ao que era ensinado e ao caráter demasiadamente humanista da formação foi consensual no simpósio. No discurso em construção, a mudança necessária implicava dotar os cursos de maior aplicabilidade, aproximando a formação das condições práticas, vivenciadas no trabalho. Esse discurso ganha dimensão política no discurso da burguesia e em sua crítica à universidade e vai fundamentar a defesa de políticas públicas voltadas a construir uma relação de maior proximidade entre as universidades e as empresas. A defesa dessa proximidade foi justificada com base no argumento de que essa proximidade poderia não somente melhorar a formação profissional dos alunos, mas também contribuir para a disseminação entre os alunos, de valores da inciativa privada e, consequentemente, contribuindo para a desqualificação do discurso da esquerda. Mas essa aproximação não deveria ser feita de forma descontrolada. Era preciso selecionar os melhores alunos que, efetivamente, frequentassem a universidade e não aqueles que, apenas, a frequentavam com objetivos políticos e subversivos.

Em linhas gerais, a crítica feita à universidade visava construir o discurso de que a radicalização do movimento estudantil era expressão de problemas organizacionais internos à universidade de que a formação dos estudantes não poderia ficar restrita ao professor e de que a ausência de uma cultura e da defesa dos valores da iniciativa privada na universidade, contribuíram para a radicalização do movimento estudantil facilitando, assim, a cooptação dos estudantes pelas lideranças da esquerda. $\bigcirc$ simpósio, organizado pelo IPES, fez jus a seu nome; afinal, discutiu a educação que convinha à direita. Fez a crítica à politização do movimento estudantil de 1968 por meio do discurso de desqualificação da política e de enaltecimento dos aspectos técnicos da formação.

Chama-nos a atenção a proximidade do discurso e das teses defendidas pelo IPES na década de 1960 com a ação ideológica feita pela direita nos dias de hoje. Um estudo recente a ser publicado pelo Instituto de Pesquisas Econômicas Aplicadas (IPEA), fundação pública vinculada ao Ministério do Planejamento, Desenvolvimento e Gestão, é elucidativo de como é feita a construção do discurso, que objetiva desqualificar a formação humanista e as ciências humanas em geral. Realizado por Thais Waideman Niquito e Adolfo Sachsida (NIQUITO; SACHIDA, 2018), pesquisadores do IPEA, os autores do texto apresentam resultados de pesquisa cujo objetivo foi verificar o efeito da inclusão das disciplinas de sociologia e filosofia no ensino médio. A tese que 
Negação da política e politização da educação: a prática discursiva do Movimento Escola sem Partido

defendem é de que a inserção dessas disciplinas produzira efeitos negativos, como a piora do desempenho dos alunos, especificamente na aprendizagem da matemática. Adolfo Sachsida tem atuado, de forma significativa, nas redes sociais, defendendo as teses do ESP, criticando o que ele define como ideologização do IPEA pela esquerda e, mais recentemente, se aproximando, politicamente, do deputado Jair Bolsonaro.

\section{O controle do discurso e das ideias na perspectiva do ESP}

Nosso objetivo, ao analisar o discurso e a ação política do ESP' na educação, é mostrar que ele é, de forma mediada, a atualização histórica do pensamento produzido pelo IDORT e o IPES em outros momentos de nossa história. Atualmente, o ESP expressa a oposição mais radical às reformas educacionais curriculares propostas pelo lulismo, especificamente ao que denomina ideologia de gênero. É parte do amplo movimento político da direita e produz um discurso, que visa legitimar e consolidar o golpe político, ocorrido em 2016.

Opera no plano político e no campo da disputa pela hegemonia por vários meios e caminhos, entre eles, a crítica à regulação feita pelo Estado dos processos educacionais, especificamente aqueles destinados à organização curricular.

A ação política mais articulada que realiza e que mais atenção desperta no ESP é sua intenção de estabelecer regras sobre o currículo e a ação do professor. Em razão disso, sua ação tem sido no sentido de interferir nos debates recentes e que tem por objetivo definir uma nova organização curricular para a educação básica, com destaque para a Base nacional Comum Curricular. Nesse caso, vários dos adeptos de suas teses deram ressonância às suas ideias nos fóruns que foram criados para discutir a BNCC. Outra ação desenvolvida se deu no campo formal da política formal, por meio da mobilização de quadros visando pressionar os espaços legislativos quando da discussão e aprovação dos planos estaduais e municipais de educação. Comum a ambas as ações é a defesa que fazem da incorporação, pela legislação, de mecanismos que definam os limites do trabalho do professor, bem como a punição àqueles que não cumprirem o estabelecido na lei. 
Aspecto central do discurso do ESP, e que tem demarcado sua atuação e inserção, no diabete curricular, é a tese que defendem acerca da necessidade de a legislação definir a fronteira entre o que eles entendem por formação e escolarização. Tese controversa, em que o papel da família e da escola seria estabelecido visando permitir que as famílias definissem o que é melhor para seus filhos no campo da formação, e a escola cuidasse da escolarização. Argumentam que a formação cabe à família, pois trata de questões religiosas, de sexualidade, de análise política, de família e da moral em geral, questões que não caberiam à escola interferir. Com isso, a escolarização deveria se ater à transmissão do conhecimento, que ficaria restrito a fatos naturais e históricos, mas tratados sem a interferência do professor. Os professores devem propiciar aos alunos o acesso ao conhecimento, mas não devem emitir opiniões, seja ela qual for. Para justificar seu discurso, apresentam exemplos de como os professores interferem e influenciam na formação dos alunos, em campos que consideram exclusivos da família: a formação política e a discussão sobre sexualidade.

No caso da formação política, a ação é centrada nos professores das disciplinas da área de humanas, especificamente de história, sociologia e filosofia. $O$ ESP defende que os professores sempre informem ao aluno, que existem diferentes interpretações sobre os fatos sociais, bem como diferentes ideais a orientar esses fatos. Dessa forma, o professor não deve jamais fazer de sua aula um meio de impor sua opinião. No caso específico desses professores, é comum o argumento de que, por serem, em sua maioria, de formação marxiana, são os que mais atuam, politicamente, nas escolas e, de certa forma, os que mais precisam ser controlados.

Entre os alvos do ESP, encontram-se as políticas que visam combater o racismo e suas formas de expressão curricular. A Lei n 10.639, de 9 de janeiro de 2003, que obrigou a inclusão, nos currículos do ensino de História e Culturas Africanas e Afro-Brasileiras e da Educação das Relações Raciais, é objeto de crítica, embora de forma dissimulada. $O$ discurso do ESP, ao afirmar a defesa da família, dos bons costumes e das normas oficiais, desqualifica e distorce a história afro-brasileira, aliando-se a grupos fundamentalistas neopentecostais em ações violentas contra os que professam religiões de origem africana. A esse movimento, soma-se a ação interna nas escolas de exclusão dos conteúdos referentes ao ensino de história e cultura africana e o debate sobre as questões étnico-raciais. 
Negação da política e politização da educação: a prática discursiva do Movimento Escola sem Partido

No caso da sexualidade, o ataque aos movimentos sociais, que tem atuado, politicamente, na construção de políticas de identidade, gênero, etnicidade, raciais e sexuais, é intenso. Nesse campo, como tem sido comum ao longo do tempo, incorpora a defesa de uma moral em que a preservação da família é central. A ação do ESP, no intento de interferir no debate específico sobre as questões de gênero e corporeidade, ganhou densidade durante o debate e o processo de elaboração do Plano Nacional de Educação (PNE). As teses, defendidas pelo ESP, partem da premissa de que há um movimento político que deseja inserir, nas escolas, certa ideologia de gênero. $\bigcirc$ ESP afirma que essa ideologia propõe uma compreensão da sexualidade humana definida por questões psicológicas e culturais, e que não existiria, portanto, uma definição biológica da sexualidade. Ela seria, portanto, construída no plano social, constituindo, assim, uma ideologia avessa aos princípios cristãos e incentivadora da homossexualidade, da mistura de sexos, da existência de banheiros mistos e do casamento de pessoas do mesmo sexo. A tese básica que defendem é de que nascemos com nossa sexualidade definida biologicamente; assim, contrariar esse dado é agir no sentido de destruir a família, perverter as crianças e destruir a sociedade.

80 A ação do ESP, nesse campo, objetiva desconstruir, no plano discursivo, o processo que visa à igualdade de gênero e de orientação sexual. Esse movimento se materializa em diversas frentes e se expressa em vários documentos internacionais e nacionais. Documentos que têm, como base, a Declaração Universal dos Direitos Humanos, editada pela ONU em 10 de dezembro de 1948, e que, no Brasil, se expressam na Resolução n 1, de 30 de maio de 2012, que institui as Diretrizes Nacionais para a Educação em Direitos Humanos, na Lei n 12.852, de 5 de agosto de 2013, que institui o Estatuto da Juventude, e legislação correlata e na Resolução n 4, de 13 de julho de 2010, que institui as Diretrizes Curriculares Nacionais para a Educação Básica, são documentos destinados a orientar ações visando combater a realidade marcada pela violência contra os direitos humanos, especificamente contra mulheres e pessoas LGBT.

discurso do ESP afirma defender a família brasileira, entendida como a família nuclear composta, hierarquicamente, pelo pai, a mãe e os filhos, e que seja resultado da relação formal definida pelo matrimônio. Fora desse modelo, tudo é taxado de desestruturador e ameaça à sociedade cristã. Desqualifica, assim, os dados que mostram que, no Brasil, há distintas formas 
de organização familiar e que elas expressam formas de viver e sentir o mundo extrapolando os limites biológicos. Assim, o ESP afirma que, somente, se pode falar em família, quando nos referimos à união entre homem e mulher, cujos papéis sociais que deles se esperam é mera materialização daquilo que foi definido por Deus e pela natureza, negada a possibilidade de que o gênero seja distinto do sexo. Com isso, se põem, de forma agressiva, contra aqueles que defendem que a escola deve problematizar essas questões, pois o gênero é uma questão definida no campo da constituição social do indivíduo.

Em síntese, o que o movimento objetiva é definir o que pode e o que não pode ser dito pelo professor em suas aulas. Sua ação mais ambiciosa, em nível nacional, foi empreendida por meio de um projeto de lei, de autoria do senador do Espírito Santo, Magno Malta, que, nesse momento, teve sua tramitação no Senado Federal estrategicamente suspensa. No geral, o projeto do senador visa instituir mudanças na Lei de Diretrizes e Bases da educação de 1996, impondo restrições e limites ao trabalho do professor, especificamente na Educação básica, que concentra cerca de 2 milhões de professores, distribuídos entre a educação infantil, o ensino fundamental e médio. Por que sua ação é tão incisiva sobre a educação básica? Por que a preocupação em controlar o trabalho de milhões de trabalhadores? $\bigcirc$ argumento veiculado é o de que a escola pública estatal, no Brasil, foi tomada pelos partidos de esquerda, que a utilizam como meio de transmissão de suas ideias. Assim, as escolas, tornaram-se a escola de um partido, o partido da esquerda.

Os adeptos do ESP utilizam as redes sociais para disseminar suas convicções e produzir consensos acerca de suas teses de controle e intervenção. Os limites analíticos que o ESP enfrenta é o mesmo daqueles que somente transitam pelo campo das ideias; eles desconsideram a realidade. Imaginar que professores têm o poder de moldar as mentes dos jovens, como se esses estivessem sujeitos, unicamente, a discursos que ocorrem nas escolas, é desconsiderar que o processo social de produção das ideias é amplamente controlado, não pelas escolas e seus professores, mas pelos meios de comunicação, possibilitados pelas diferentes mídias, bem como pelo poder atrativo da indústria do entretenimento.

Seria um erro primário do ESP se essa fosse a intenção final, mas, nesse caso, ela pode ser outra. Em um momento que o discurso amplo do capital afirma ser necessário à contenção dos gastos públicos, em nome da famigerada busca do equilíbrio fiscal, atacar, politicamente, e tentar interferir 
Negação da política e politização da educação: a prática discursiva do Movimento Escola sem Partido

no controle da ação política de segmento importante de trabalhadores do setor público faz sentido. Mecanismos de controle e diminuição do gasto público atingem, diretamente, os trabalhadores da educação, que precisam ser contidos e restringidos em sua capacidade de luta política. Atacar os professores e as escolas como espaços de doutrinação e de disseminação de ideologias de gênero, como o faz o ESP, o habilita perante parcela da sociedade como interlocutor de seus interesses e o legitima na defesa da ação restritiva que preconiza nas escolas.

A ação política do ESP, ao tentar controlar os professores, procura também controlar os mecanismos de representação dos trabalhadores, ou seja, os sindicatos. Como o faz? Seus interlocutores, além dos espaços de divulgação nas redes e mídias privadas, têm ocupado espaços na mídia pública. Uma estratégia comum, em sua ação, é a de sempre levantarem a questão: quem são os críticos do ESP ou quem a ele se opõe? A resposta pronta é a de que os sindicatos de professores e os movimentos sociais de identidades são seus únicos críticos. Buscam, assim, o controle sobre o que falam os professores e também sobre suas organizações políticas, em ambos os casos procurando fragilizá-las e desqualificá-las no debate público, contribuindo para que o dis-

82 curso de desmonte do orçamento público da educação seja mais palatável.

Merece, também, ser observado o fato de que a ação política do ESP tem, como alvo, uma parcela significativa da população. A educação básica, no Brasil, possui cerca de oito milhões de crianças somente na educação infantil, vinte e oito milhões de alunos no ensino fundamental e cerca de oito milhões no ensino médio. Como atuar, nesse espaço, e fazer suas ideias circularem? Seria necessária uma ação de proporções gigantescas e de difícil execução. Assim, na impossibilidade de disputar, ideologicamente, o espaço escolar com os professores e de disseminar sua doutrina que, segundo o ESP, são todos de esquerda, o movimento ataca esses professores, objetivando desqualificá-los, diminuir a importância do trabalho que realizam e desvalorizá-los socialmente.

Chama-nos atenção, também, o fato de que os articuladores do ESP, e seus defensores públicos, não se preocuparem com as causas e problemas que afetam a educação pública no Brasil. Não se discutem a estrutura das escolas tampouco as condições de trabalho dos professores. Não se discute a enorme dificuldade apresentada pelos alunos no domínio de conhecimentos básicos, especificamente da leitura e da escrita. Não se discutem as condições de vida desses alunos e as dificuldades que enfrentam para permanecer na escola. 
Não se discutem o salário dos professores, sua carreira, e muito menos, as dificuldades enfrentadas em sua formação. Assim, se o ESP está preocupado com os rumos da educação escolar brasileira, com as dificuldades enfrentadas pelos alunos, o ESP deveria considerar outras questões em sua crítica.

Quando centramos nossa atenção no discurso que o ESP produz e sua intenção de controlar, ideologicamente, a escola, chama a atenção o seguinte fato. Estaria a escola pública brasileira controlada por ideias disseminadas pela esquerda política? $\bigcirc$ que a história nos mostra não são professores questionando valores ou ideias que defendem o que está estabelecido socialmente. Não tem sido essa a ação dos professores e das escolas. Pelo contrário, a educação escolar tem contribuído mais com a disseminação de valores que reproduzem ideias dominantes, do que ideias que os contestam. $\bigcirc$ discurso da meritocracia, disseminado nas escolas, de forma, às vezes, ingênua, é feito sem qualquer análise crítica acerca das formas desiguais com que, no capitalismo, os processos de apropriação do conhecimento ocorrem, legitimando o mérito de alguns em detrimento do fracasso de muitos. Dessa forma, o papel da escola não tem sido o de disseminar a lógica da solidariedade e da igualdade; pelo contrário, a escola tem sido aquela que, em uma sociedade que naturaliza a desigualdade, encontra os melhores alunos, os reconhece e legitima socialmente.

Outro aspecto acerca do currículo que não é mencionado pelo ESP é de que os conteúdos que os professores devem transmitir a seus alunos precisam estar articulados com o projeto político-pedagógico da escola. Dessa forma, o que deve ser ensinado urge ser discutido no momento de elaboração desse projeto. Como elaborar esse projeto sem que diferentes concepções de formação, que os professores possuem, se manifestem? Não seria esse o momento em que a propalada tese do ESP, de que a escola deve contemplar diferentes interpretações sobre os processos sociais, se manifestasse? Que as diferentes concepções sobre a vida aflorassem, fossem discutidas e produzissem consensos possiveis sobre o que deve ser ensinado? Por que o ESP não toma, como sua bandeira, a defesa de que os currículos escolares devam ser objeto de amplo debate social? Não podemos exigir da direita que ela não seja de direita, pois isso exigiria o que ela não pode fazer, ou seja, "[...] captar a forma de uma totalidade exige um raciocínio rigoroso e cansativo, o que vem a ser uma das razões por que aqueles que não tem necessidade de fazê-lo 
Negação da política e politização da educação: a prática discursiva do Movimento Escola sem Partido

venham a se maravilhar com a ambiguidade e a indeterminação" (EAGLETON, 1998, p. 211.

\section{Considerações finais}

Ao analisarmos o discurso produzido pelo ESP, verificamos que seus articuladores partem de uma premissa que é consensual entre educadores, ou seja, que a escola deve contemplar a diversidade teórica e ideológica. $\bigcirc$ mesmo não pode ser dito sobre a tese central que os defendem, de que os professores e as escolas são espaços de doutrinação, ocupados pela esquerda. É uma conclusão equivocada e falsa, própria de quem não conhece o cotidiano das escolas, os jovens que nelas estudam e, muito menos, os professores e diretores que nelas trabalham. Podemos, também, lembrar aos homens puros do ESP que a sua preocupação com a ideologia marxista é exagerada, visto que intelectuais, responsáveis pela construção recente do pensamento conservador no Brasil, como Golbery do Couto e Silva, Jarbas Vasconcelos e Delfin Netto, figuras atuantes durante a ditadura militar, foram leitores de Marx e dos marxistas, pois entendiam a importância desses para a sua luta política.

Devemos, também, lembrar ao ESP que a boa crítica começa com a leitura sistemática e a compreensão das ideias que se deseja criticar. Lendo um pouco de Marx poderiam descobrir como a construção da análise e a crítica que fez foi tributária do pensamento de seu tempo. A dialética de Friedrich Hegel e a economia política clássica de Adam Smith e David Ricardo foram fundamentais na elaboração da crítica feita por Marx ao capital.

$\bigcirc$ Brasil teve pensadores de direita, que foram leitores críticos do pensamento da esquerda. Mencionamos, aqui, a título de exemplo, José Guilherme Alves Melchior. Hoje, os expoentes da crítica são o idealizador do ESP, Miguel Nagib e o senador Magno Malta. Não é pequena a diferença.

Não esperamos que o ESP seja a atualização histórica de movimentos da direita como os idealizados pelo IDORT e IPES. Talvez estejamos cobrando dos articuladores e ideólogos do ESP o que eles não têm a oferecer. Não que esperamos deles a clareza e a perspectiva histórica que estiveram presentes, em outros tempos, em articuladores como Roberto Simonsen e Roberto Campos. Esses não somente foram conhecedores do debate ideológico, como também personagens influentes no debate ideológico, travado pela direita. 
Na prática, o que o ESP representa é a cultura da vigilância e do controle sobre o que é dito, uma perspectiva de política em que seus agentes sejam os alunos transformados em alcaguetes e dedos-duros, fiscais do bom comportamento e da boa moral e que comuniquem a seus pais qualquer ação subversiva dos professores. A esses, restaria somente a mordaça ou o império da lei.

ESP possui um discurso, que é parte do pensamento que a direita produz, que se expressa na educação, por meio de uma razão conservadora, autoritária e impositiva. Para o historiador Leandro Karnal, não passa de uma grande falácia, produzida por ignorantes no debate ideológico e que tentam impor sua concepção de mundo por meio do cerceamento do trabalho do professor.

encontro entre as concepções restritivas e de controle sobre o discurso disseminadas pelo ESP com o pragmatismo neoliberal, quando transpostas para o debate escolar, produz mudanças significativas na compreensão que se tem do papel da escola. Ao definir a família como lócus da formação moral, reduz as expectativas postas pelo cotidiano imediato, com a consequente desvalorização do conhecimento objetivo. Por outro lado, em nome de despolitizar o debate educacional, o politiza em bases conservadoras, reduzindo a dimensão e importância da escola a essas demandas. Assim, as políticas curriculares tornam-se meio de disseminação e de produção de novos significados à prática escolar, controlando o trabalho dos professores e disseminando uma concepção de sociedade que atenda aos interesses conservadores.

Consideramos pertinente encerrar este texto, que analisa o ESP e o pensamento conservador que produz, mencionando a importância de afirmar a escola como espaço da disputa política e de produção da crítica social. Terry Eagleton, em seu clássico texto, As ilusões do pós-modernismo, de 1998, ao se referir às teses pós-modernas assentadas no descentramento, na crítica aos processos normativos, na instabilidade e no ocasional, fazia a seguinte questão: "Se os fundamentos acabaram, por que existe tanto fundamentalismo por aí?" Na sequência, ao criticar o distanciamento pós-moderno da política e a perspectiva nilista, inquiria: "Se a crítica fosse mesmo desinteressada, por que alguém ia perder tempo praticando-a?" (EAGLETON, 1998, p. 27). No texto, ao fazer uma acalorada e provocativa crítica aos fundamentos do pensamento pós-moderno, o autor nos ajuda a compreender o momento político 
Negação da política e politização da educação: a prática discursiva do Movimento Escola sem Partido

brasileiro, eivado de contradições, em que discursos são anunciados como portadores de verdades eternas, desideologizadas, despolitizadas e desistoricizadas. Nesse sentido, o ESP expressa um discurso político fundamentalista, irracional e autoritário. É a forma de politizar o debate educacional, por meio de um discurso de despolitização da educação.

As formas e faces com que a direita procura demarcar o terreno do debate educacional e impor sua forma de compreender o mundo, constituiem processos que fazem parte da história da educação brasileira. $\bigcirc$ ESP pode até não ter o charme e a grife que caracterizam outras expressões políticas do irracionalismo contemporâneo, cultuadas em espaços acadêmicos os mais diversos e portadoras de discursos mais sofisticados. Pelo contrário, o que caracteriza o ESP é o discurso simples, direto e desprovido de argumentação filosófica. Sua busca é simples e objetiva; a escola não deve ser espaço para manifestação e expressão de posições políticas. Nesses termos, a escola deve ser um espaço desideologizado, despolitizado e desistoricizado. A simplicidade e objetividade com que expressa seus fundamentos, constitui o perigo que representa e abre caminho para seu fundamentalismo. Mas esse perigo não é novo, nem inédito, como o mostram as ações do IDORT e do IPES.

\section{Nota}

1 As referências feitas no texto às ideias defendidas pelo ESP foram extraídas da página que o movimento disponibiliza na internet, no endereço: https://www.programaescolasempartido. org/. A consulta que fizemos foi feita em: 20 mar. 2018.

\section{Referências}

AÇÃO EDUCATIVA (Org.). A ideologia do movimento Escola Sem Partido. 20 autores desmontam o discurso. São Paulo: Ação Educativa, Pesquisa e Informação, 2016.

ALMEIDA, Stela Borges de. Educação, história e imagem: um estudo do colégio Antônio Vieira através de uma coleção de negativos em vidro dos anos 20-30. 1999. 284f. Tese (Doutorado em Educação) - Programa de Pós-Graduação em Educação, Universidade Federal da Bahia, Salvador, 1999.

ANTONACCl, Maria Atonieta Martines. A vitória da razão? $\bigcirc$ Idort e a sociedade paulista. São Paulo: Marco Zero/CNPq, 1993. 
DREIFUSS, René Armand. A conquista do Estado - ação política, poder e golpe de classes. Petrópolis: Editora Vozes, 1981.

EAGLETON, Terry. As ilusões do pós-modernismo. Tradução Elisabeth Barbosa. Rio de Janeiro: Jorge Zahar Editor, 1998.

FRIGOTTO, Gaudêncio (Org.). Escola "sem" partido: esfinge que ameaça a educação e a sociedade brasileira. Rio de Janeiro: EdUERJ/LPP, 2017.

INSTITUTO de Pesquisas e Estudos Sociais. A educação que nos convém. Rio de Janeiro: Apec, 1969.

MELO, Demian Bezerra (Org.). A miséria da historiografia - uma crítica ao revisionismo contemporâneo. Rio de Janeiro: Consequência, 2014.

MORAES, Carmen Sylvia Vidigal. O ideário republicano e a educação: ○ Colégio "Culto à Ciência" de Campinas (1869-1892). 1981. Dissertação (Mestrado em Educação) Programa de Pós-Graduação em Educação, Universidade de São Paulo, São Paulo, 1981. NIQUITO, Thais Waideman; SACHSIDA, Adolfo. Efeitos da inserção das disciplinas de filosofia e sociologia no ensino médio sobre o desempenho escolar. Rio de Janeiro: IPEA, 2018. (Relatório de Pesquisa para impressão).

PAULO NETTO, José. Pequena história da ditadura brasileira (1964-1985). São Paulo: Cortez Editora, 2014.

SINGER, André. Os sentidos do lulismo: reforma gradual e pacto conservador. São Paulo: Companhia das Letras, 2012.

Prof. Dr. Celso do Prado Ferraz de Carvalho Universidade Nove de Julho de São Paulo Departamento de Educação

Programa de Pós-Graduação em Educação Líder do Grupo de Pesquisa em Política e Gestão Educacional (UNINOVE/CNPq) E-mail: cpfcarvalho@gmail.com Recebido 15 jun. 2018 Aceito 3 set. 2018 